\title{
Oxidation of PCEA nuclear graphite by low water concentrations in helium *
}

Cristian I Contescu, ${ }^{\mathrm{a}, \dagger}$ Robert W Mee, ${ }^{\mathrm{b}}$ Peng Wang, ${ }^{\mathrm{a}, 1}$ Anna V Romanova, ${ }^{\mathrm{b}}$ and Timothy D Burchell ${ }^{\mathrm{b}}$ 


\begin{abstract}
Accelerated oxidation tests were performed to determine kinetic parameters of the chronic oxidation reaction (i.e. slow, continuous, and persistent) of PCEA graphite in contact with helium coolant containing low moisture concentrations in high temperature gas-cooled reactors. To the authors' knowledge such a study has not been done since the detailed analysis of reaction of H-451 graphite with steam [Velasquez, Hightower, Burnette, 1978]. Since that H-451 graphite is now unavailable, it is urgently needed to characterize chronic oxidation behavior of new graphite grades that are being considered for use in gas-cooled reactors. The Langmuir-Hinshelwood mechanism of carbon oxidation by water results in a non-linear reaction rate expression, with at least six different parameters. They were determined in accelerated oxidation experiments that covered a large range of temperatures (800 to 1100 ${ }^{\circ} \mathrm{C}$ ), and partial pressures of water (15 to $850 \mathrm{~Pa}$ ) and hydrogen (30 to $150 \mathrm{~Pa}$ ) and used graphite specimens thin enough $(4 \mathrm{~mm})$ in order to avoid diffusion effects. Data analysis employed a statistical method based on multiple likelihood estimation of parameters and simultaneous fitting of non-linear equations. The results show significant material-specific differences between graphite grades PCEA and $\mathrm{H}-451$ which were attributed to microstructural dissimilarity between the two materials. It is concluded that kinetic data cannot be transferred from one graphite grade to another.
\end{abstract}




\section{Introduction}

Nuclear grade graphite is the moderator and a major structural component of High Temperature Gas-Cooled Reactors (HTGR). Although chemically stable in inert and reducing gas environments, graphite is susceptible to oxidation by oxygen, carbon dioxide, and water at the high temperatures encountered in the HTGR. Under normal operating conditions graphite components will be in contact with high purity helium used as coolant. Even though the chemical composition of the coolant will be strictly controlled, the gas will have slightly oxidizing potential because of the need to protect special alloys against carburization which would occur in a reducing gas environment. Under these conditions a slow, chronic oxidation will occur at the exposed surfaces of graphite components. It is expected that graphite chronic oxidation during normal operation will be caused in principal by the presence of water traces in helium. The partial pressures of gas impurities in the He coolant corresponding to several HTGR designs are shown in Table 1 [1-5]

Table 1: $\quad$ Helium coolant properties in different variants of gas cooled reactors

\begin{tabular}{|c|c|c|c|c|c|c|c|c|c|}
\hline & \multicolumn{7}{|c|}{ Partial pressure $(\mathrm{Pa})$} & \multirow{2}{*}{$\begin{array}{c}\text { Total pressure } \\
(\mathrm{MPa}) \\
\end{array}$} & \multirow{2}{*}{$\begin{array}{c}\text { Temperature } \\
\text { in/out }\left({ }^{\circ} \mathrm{C}\right) \\
\end{array}$} \\
\hline & $\mathrm{H}_{2} \mathrm{O}$ & $\mathrm{H}_{2}$ & $\mathrm{CO}$ & $\mathrm{O}_{2}$ & $\mathrm{~N}_{2}$ & $\mathrm{CO}_{2}$ & $\mathrm{CH}_{4}$ & & \\
\hline DRAGON, UK (1964-75) & 0.1 & 2 & 1.2 & $\mathrm{n} / \mathrm{a}$ & 0.3 & $<0.04$ & 0.3 & 2 & $350 / 750$ \\
\hline Peach Bottom, USA (1967-74) & 1.1 & 20.2 & 1.1 & $\mathrm{n} / \mathrm{a}$ & 1.5 & $<1.1$ & 2.2 & 2.25 & $377 / 750$ \\
\hline AVR, Germany (1967-88) & 3 & 30 & 10 & $\mathrm{n} / \mathrm{a}$ & $\mathrm{n} / \mathrm{a}$ & 10 & $\mathrm{n} / \mathrm{a}$ & 1.1 & $270 / 750-950$ \\
\hline Fort St. Vrain, USA (1976-79) & $<5$ & $10 \ldots 35$ & $5 \ldots 50$ & $\mathrm{n} / \mathrm{a}$ & $\mathrm{n} / \mathrm{a}$ & $2 \ldots 14$ & $0.5 \ldots 4$ & 4.8 & $400 / 775$ \\
\hline HTR-10, China (2003) & $<1.4$ & $<21$ & $<21$ & $\mathrm{n} / \mathrm{a}$ & $<7$ & $\mathrm{n} / \mathrm{a}$ & $<7$ & 7 & $490 / 850$ \\
\hline HTR-PM, China (project) & 14 & 210 & 210 & 1.4 & 14 & 42 & 35 & 7 & $250 / 750$ \\
\hline HTTR, Japan (1998-present) & $<0.8$ & $<12$ & $<12$ & $\mathrm{n} / \mathrm{a}$ & $<0.8$ & $<2.4$ & $<2$ & 4 & $395 / 950$ \\
\hline NPH /HHT & 0.3 & 100 & 8 & $\mathrm{n} / \mathrm{a}$ & $1 . .2$ & $\mathrm{n} / \mathrm{a}$ & 10 & 0.2 & $\mathrm{n} / \mathrm{a} /<950$ \\
\hline PNP & 0.3 & 100 & 3 & $\mathrm{n} / \mathrm{a}$ & $<1$ & $\mathrm{n} / \mathrm{a}$ & 4 & 0.2 & $\mathrm{n} / \mathrm{a} /<950$ \\
\hline AGCNR & 0.4 & 80 & 8 & $\mathrm{n} / \mathrm{a}$ & $<4$ & 0.04 & 4 & 0.2 & $\mathrm{n} / \mathrm{a} /<950$ \\
\hline PBMR & 0.04 & 5 & 2 & $<0.01$ & $\mathrm{n} / \mathrm{a}$ & $\mathrm{n} / \mathrm{a}$ & $\mathrm{n} / \mathrm{a}$ & 9.0 & $400 / 900$ \\
\hline HTGR prismatic design & $0.7-1.4$ & $1.4-7.0$ & $1-3$ & $\mathrm{n} / \mathrm{a}$ & $<1.4$ & $<0.7$ & $<0.7$ & 7.0 & $540 / 900$ \\
\hline
\end{tabular}

$\mathrm{NPH}=$ nuclear power process heat; HHT = high-temperature helium turbine systems; PNP = prototype nuclear process heat; AGCNR = advanced gas-cooled nuclear reactor; $\mathrm{PBMR}=$ pebble bed modular reactor. Adapted from refs. [1-5].

A large body of experimental results accumulated during years of intense R\&D activity in USA, UK, Germany, Japan, China etc, provides confidence that operation of HTGR is safe over extended periods of time, and that the oxidative degradation of graphite components under the effect of impurities in the coolant circuit will be minimal during normal operation conditions. However, qualification of new graphite grades in the USA for HTGR use requires experimental characterization of gasification kinetics for the new candidate graphite grades. The challenge comes from the fact that oxidation kinetics follows a 
complex, non-linear mechanism where the accelerating action of oxidant species (water in this case) is balanced by the retarding action of gas product species (e.g. hydrogen) which act as inhibitors. This mechanism, known as the Langmuir - Hinshelwood (L-H) mechanism, is well documented in the literature on graphite oxidation [6-9]. Data collection is also challenged by the need of using conditions where oxidation is fast enough to afford measureable rates, but not too fast, to avoid perturbations caused by slow mass transport effects. Maintaining the purity of gas atmosphere and of graphite surfaces are key conditions that ensure repeatability and reproducibility of results. Because of these challenges, there have been only a few systematic and reliable measurements of the slow oxidation rates caused by impurities in the coolant helium. The most comprehensive of them was performed by Velasquez, Hightower, and Burnette at General Atomic (GA) Company in 1978 [10]. They used the nuclear graphite grade H-451, developed at that time in the U.S. for gas-cooled reactors. This graphite was used in the Fort St. Vrain reactor, but it is no longer available. The report by Velasquez et al. contains explicit parametric equations describing the dependence of oxidation rate on partial pressures of water and hydrogen and on temperature. Later, Richards [11] used the kinetic parameters of the L-H mechanism available in the GA report [10] and calculated the density profile at the surface of water-oxidized H-451 graphite during prolonged exposure to helium coolant in normal operating conditions. He concluded that gasification of graphite elements will be confined at the coolant-graphite interface, and therefore corrosion by steam should not affect normal operation of HTGR, provided steam concentration is kept below $0.01 \mathrm{~Pa}$. This conclusion was reiterated by more recent estimates, all based on the same graphite-specific parameters reported by GA for reaction of $\mathrm{H}-451$ grade with water [12-16].

There is ample evidence that the properties of nuclear graphite depend strongly on the raw material type, microstructure (including the grain size), and impurity level. This refers not only to mechanical, thermal, or electrical properties, but also to the chemical stability in various environments [17-21]. All the documented evidence raise questions on the legitimacy of making predictions on the behavior of the new graphite grades in normal operating conditions based on kinetic parameters measured for a graphite grade no longer available (H-451).

This paper reports results of accelerated oxidation tests of the new PCEA grade nuclear graphite manufactured in the U.S. by GrafTech International Ltd. The accelerated oxidation experiments at low water concentration in high purity helium were designed for laboratory test conditions with two goals in sight: to keep relevance to chronic (slow) oxidation expected in HTGR normal operating conditions, and at the same time to run the program within reasonable time and budget parameters. 


\section{Experimental}

PCEA is a medium grain graphite ( $0.8 \mathrm{~mm}$ maximum grain size) manufactured from a petroleum coke using an extrusion process. Kane et al. [22] [showed by optical microscopy that about $70 \%$ of filler particles are acicular in shape with mean length of $\sim 167 \mu \mathrm{m}$ and aspect ratio close to 3.2; spherical filler particles are also present, with an average diameter of $\sim 99 \mu \mathrm{m}$. This graphite has narrow shrinkage cracks oriented randomly and larger cracks aligned with the long axis of acicular filler particles.

The specimens used for oxidation experiments were extracted from a PCEA graphite billet procured from GrafTech International in 2008. A sub-block of equatorial orientation was cut at halflength from the original cylindrical billet and was further purified by gas extraction. The main impurities remaining after purification were $\mathrm{Si}$ (1.5 ppm wt), S (4.6 ppm wt), P (0.22 ppm wt), V (0.28 ppm wt) and Mo (0.35 ppm wt) based on glow-discharge mass-spectrometry (GDMS) analysis done at Shiva Technologies in Syracuse, NY (now part of Evans Analytical Group). The specimens used for oxidation experiments were machined from the purified sub-block, using lubricant-free conditions and iron-free tools. All specimens were of cylindrical shape, $20.00 \pm 0.05 \mathrm{~mm}$ in length and $4.00 \pm 0.02 \mathrm{~mm}$ diameter. Before use specimens were sonicated in acetone, dried in air at $110{ }^{\circ} \mathrm{C}$ and handled only with cotton gloves.

Experiments were carried out in the thermogravimetric analyzer TAG 16/18 (from SETARAM, France). This very sensitive, highly stable dual thermoanalyzer has symmetrical configuration designed to minimize buoyancy effects normally encountered in vertical furnace arrangements. A quartz cylinder of identical shape and size as the graphite specimens was used as inert reference.

The carrier helium gas was delivered from a 16-bottle battery (Air Liquide, USA) containing ultra-high purity (UHP) He (> 99.999 vol \%) with traces of water $(0.2-0.3$ ppmv), oxygen $(0.8-1.7$ ppmv), and hydrocarbons ( $<0.1 \mathrm{ppmv})$. The dry He stream was split in two lines controlled by calibrated mass-flow controllers. A line with lower flow rate (up to $0.5 \mathrm{~L} / \mathrm{min}$ ) was passed through a bubbler maintained at controlled temperature $\left( \pm 0.05{ }^{\circ} \mathrm{C}\right)$ which contained plasma-grade water (Sigma-Aldrich, USA). The humid He was reunited with the line of higher flow rate (up to $5 \mathrm{~L} / \mathrm{min}$ ) of dry UHP He. A third mass-flow controller (up to $0.25 \mathrm{~L} / \mathrm{min}$ ) was used to introduce a composition-certified gas (Air Liquide, USA) containing $\mathrm{H}_{2}(1.00 \pm 0.02 \% \mathrm{vol})$ and UHP $\mathrm{He}$ (balance). The gas composition was adjusted by controlling the temperature of the water bath hosting the bubbler and the flow rate ratios between the three gas lines. The humidity level in the mixed gas used for oxidation was measured by a chilled mirror hygrometer (CR-4 from Buck Research Instruments LLC, USA) equipped also with an internal pressure gauge. The gas leaving the hygrometer was fed to the furnace of the TAG instrument and then was exhausted at the ambient pressure in the lab. The partial pressure of water (and hydrogen, when used) in the reaction chamber of the TAG instrument was calculated from the frost point 
temperature and internal pressure measured by the hygrometer (and from the flow rate and known $\mathrm{H}_{2}$ concentration in $\mathrm{H}_{2} / \mathrm{He}$ mixture). The partial pressures, $P_{\mathrm{H} 2 \mathrm{O}}$ and $P_{\mathrm{H} 2}$, were corrected for the actual barometric pressure in the laboratory, which was continuously recorded. Additional purification of water and oxygen traces from all inlet gas lines was done with Oxy-purge type $\mathrm{N}$ traps (Fisher Scientific) and Drierite water traps (Fisher Scientific). Drierite traps are rated to $0.2 \mathrm{~Pa} \mathrm{H}_{2} \mathrm{O}$ at a higher flow rate than that used in the experiments. However, the baseline water vapor pressure from hygrometer readings was about $2 \mathrm{~Pa}$. This suggests that hygrometer readings were less reliable at very low frost temperatures (- 55 ${ }^{\circ} \mathrm{C}$ ) and in reality the water vapor pressure in the UHP carrier was lesser than the lower end of scale readings of the hygrometer (probably in the $0.02-0.03$ Pa range, based on specifications for the Drierite trap material).

A LabView software application (National Instruments) was used to control all flow rates and water bath temperature, and to collect data from the hygrometer (frost point and internal pressure) and information on ambient temperature and pressure. A mass spectrometer (DCS 350 from Pfeiffer Vacuum) was intermittently used to verify the purity of the oxidation gas inside the reaction chamber. Occasional formation of measurable amounts of $\mathrm{CO}$ and $\mathrm{H}_{2}$ from the oxidation reaction (Scheme I) was also detected:

$$
\mathrm{C}_{(\mathrm{s})-}+\mathrm{H}_{2} \mathrm{O}_{(\mathrm{g})}=\mathrm{CO}_{(\mathrm{g})}+\mathrm{H}_{2(\mathrm{~g})} \quad \text { Scheme I }
$$

The rate of weight loss by gasification was measured over a broad range of temperatures (800 to $1100{ }^{\circ} \mathrm{C}$ ) and partial water pressures $(15$ to $850 \mathrm{~Pa}$ ). In several experiments hydrogen was also added to moist helium (partial pressures between 30 and $150 \mathrm{~Pa}$ ) to determine the inhibition of gasification rates caused by $\mathrm{H}_{2}$, which is a reaction product of oxidation by water. In all experiments the total flow rate was kept constant at $1.5 \mathrm{~L} / \mathrm{min}$, and the total pressure in the reaction chamber was equal to the barometric pressure in the laboratory.

In a typical experiment, the specimens were first outgassed in situ at $1200{ }^{\circ} \mathrm{C}$ in pure helium for 1 $\mathrm{h}$. Then the temperature was lowered to the lowest test temperature and the oxidizing gas with preset composition was introduced. Each run, starting with a fresh specimen, comprised between two and six constant temperature segments during which the weight changes were recorded as a function of time. After each segment (between 3 and 8 hours long) the temperature was changed fast (5-10 min) to the next segment. No differences in the oxidation rates were observed between runs with either increasing or decreasing order of constant temperature segments. In the experimental conditions selected, the maximum weight loss experienced by each specimen was usually below $1.5 \%$ (3.5\% for most aggressive conditions).

Not all experimental observations (more than 300 data) could be used for data analysis. About one third of data, which showed deviant behavior from the model-supported trends with temperature and 
pressure were discarded. ${ }^{1}$ Rather than concluding that the L-H model is invalid, it was assumed that most deviations were caused by local structural or compositional factors in some graphite specimens.

Moreover, as will be shown later, statistical data analysis confirmed that the main source of experimental variability were random differences between local properties of individual graphite specimens. These variations are explicable given that the diameter of all specimens $(4 \mathrm{~mm})$ was only five times larger than the maximum grain size of PCEA graphite $(0.8 \mathrm{~mm})$. Indeed, density measurements of individual specimens showed position-dependent variations in the graphite billet $\left(1.792 \pm 0.008 \mathrm{~g} / \mathrm{cm}^{3}\right.$ at internal positions, versus $1.795 \pm 0.016 \mathrm{~g} / \mathrm{cm}^{3}$ at external positions).

\section{Data reduction}

The mechanism of graphite oxidation by water is complicated by the fact that hydrogen formed as a byproduct has a well-documented inhibition effect. This introduces non-linearity in the rate equation of the oxidation reaction shown in Scheme I, as was first proposed by Gadsby et al. [6.7] and later confirmed by Blakely and Overholser [8,9]:

Rate $=\frac{k_{1} P_{\mathrm{H} 2 \mathrm{O}}}{1+k_{2}\left(P_{\mathrm{H} 2}\right)^{n}+k_{3} P_{\mathrm{H} 2 \mathrm{O}}}$

where Rate is the instantaneous reaction rate $\left(\mathrm{s}^{-1}\right)$, and the kinetic rate constants $k_{i}(i=1,2,3)$ have Arrhenius type temperature dependence with specific values for the activation energy and frequency factors $E_{i}$ and $A_{i}(i=1 \ldots 3)$ :

$k_{i}=A_{i} e^{-\frac{E_{i}}{R T}}$

where $\mathrm{R}=8.314 \mathrm{~J} \mathrm{~mol}^{-1} \mathrm{~K}^{-1}$ is the universal gas constant. This formal representation of oxidation rates describes the empirical observation that an increase of $P_{\mathrm{H} 2 \mathrm{O}}$ accelerates the reaction, while an increase of $P_{\mathrm{H} 2}$ slows it. The inhibition is caused by the competition between $\mathrm{H}_{2}$ and $\mathrm{H}_{2} \mathrm{O}$ for available reaction sites on carbon's surface, as typical for heterogeneous chemical reactions following the more general L-H mechanism. In the detailed mechanism initially proposed by Gadsby, surface sites are blocked by adsorbed molecular $\mathrm{H}_{2}$ as shown below:

$$
\mathrm{C}_{\mathrm{f}}+\mathrm{H}_{2} \mathrm{O}(\mathrm{g}) \underset{j_{1}}{\stackrel{i_{1}}{\rightarrow}} \mathrm{C}\left(\mathrm{H}_{2} \mathrm{O}\right)
$$

\footnotetext{
${ }^{1}$ Reaction rates are expected to increase with temperature and partial pressure of water. When faster rates were occasionally measured at low temperatures or low water pressure, in flagrant deviation from the common trend of data at similar conditions, these data were discarded. The deviations may have been caused by local impurities in the graphite specimens. Indeed, in most of discarded experiments the final weight loss was much higher than expected, and the oxidized samples showed external pits indicative of higher than average local oxidation rates. Moreover, graphite is a non-homogeneous composite material which shows local variation of properties throughout its volume. They result from the tortuosity and connectivity of the pore structure, as recently documented by systematic X-ray tomography measurements.
} 


$$
\begin{aligned}
& \mathrm{C}\left(\mathrm{H}_{2} \mathrm{O}\right) \stackrel{j_{3}}{\rightarrow} \mathrm{CO}_{(\mathrm{g})}+\mathrm{H}_{2(\mathrm{~g})} \\
& \mathrm{C}_{\mathrm{f}}+\mathrm{H}_{2(\mathrm{~g})} \stackrel{\stackrel{i_{2}}{j_{2}}}{\rightarrow} \mathrm{C}\left(\mathrm{H}_{2}\right)
\end{aligned}
$$

This corresponds to the following explicit rate equation:

$$
\text { Rate }=\frac{\frac{i_{1} j_{3}}{i_{1}+j_{2}} P_{\mathrm{H} 2 \mathrm{O}}}{1+\frac{i_{2}}{j_{2}}\left(P_{\mathrm{H} 2}\right)^{n}+\frac{i_{1}}{j_{1}+j_{2}} P_{\mathrm{H} 2 \mathrm{O}}}
$$

which is formally equivalent to equation (1), and suggests that the rate constants $k_{i}$ in the formal equation are actually combinations of the elementary reaction rates shown in Scheme II. The Gadsby reaction scheme was used by Velasquez et al. [10] in the GA report on oxidation by water of H-451 graphite. However, Giberson and Walker [23] argued that atomic hydrogen, rather than molecular, is the site blocker in the temperature range of gasification by water. They proposed an alternate reaction scheme

$$
\begin{aligned}
& \mathrm{C}_{\mathrm{f}}+\mathrm{H}_{2} \mathrm{O} \stackrel{i_{1}}{\rightarrow} \mathrm{C}(\mathrm{O})+\mathrm{H}_{2} \\
& \mathrm{C}_{\mathrm{f}}+1 / 2 \underset{2}{\mathrm{H}_{2}} \stackrel{\stackrel{i_{2}}{j_{2}}}{\rightarrow} \mathrm{C}(\mathrm{H}) \\
& \mathrm{C}(\mathrm{O}) \stackrel{i_{3}}{\rightarrow} \mathrm{CO}+\mathrm{C}_{\mathrm{f}}
\end{aligned}
$$

which leads to a different form of the explicit kinetic equation:

$$
\text { Rate }=\frac{i_{1} P_{\mathrm{H} 2 \mathrm{O}}}{1+\frac{i_{2}}{j_{2}}\left(P_{\mathrm{H} 2}\right)^{1 / 2}+\frac{i_{1}}{i_{3}} P_{\mathrm{H} 2 \mathrm{O}}}
$$

In this form, the reaction order $n=0.5$ reflects dissociation of molecular $\mathrm{H}_{2}$. The hypothesis of dissociative hydrogen chemisorption on carbon was confirmed by recent experimental and computational results on $\mathrm{H}_{2}$ interaction with carbon. It is now proven that molecular adsorption of $\mathrm{H}_{2}$ is very weak at room temperature, and highly improbable at elevated temperatures [24]. In contrast, atomic $\mathrm{H}$ is strongly chemisorbed on carbon atoms at graphene edges, and the reactivity increases with the increase of temperature [25]. These facts provide strong support to reaction scheme III where inhibition is caused by strong chemisorption of atomic $\mathrm{H}$ at high temperatures. Our own observations have indeed confirmed that inhibition by hydrogen intensifies as the temperature increases, which led us to assume $n=0.5$ in the following analysis. Indeed, a sensitivity analysis study [26] of the variation introduced by various parameters of the L-H mechanism in eq. (1) shows that the rate constant $k_{l}$ is by far the most important parameter: both the frequency factor $A_{l}$ and the activation energy $E_{l}$ have important effects on oxidation rates, and the effect of $E_{l}$ is more significant. Accurate determination of these two parameters is of 
paramount importance for prediction of oxidation rates and for extrapolation at lower $P_{\mathrm{H} 2 \mathrm{O}}$ and temperatures beyond the range of experimental measurements. The parameters associated with $k_{3}$, which introduces the non-linearity with respect to $P_{\mathrm{H} 2 \mathrm{O}}$ are less sensitive. The rate constant $k_{2}$ which introduces the inhibition effect of $\mathrm{H}_{2}$ becomes important only at high temperature and high $P_{\mathrm{H} 2}$, where the effect of $E_{3}$ is stronger than that of $A_{3}$. The kinetic order $n$ has a less important effect compared with the kinetic constants.

\section{Determination of kinetic constants}

In the GA study of 1978, Velasquez et al. [10] used a linearization of eq. (1) to determine the kinetic constants step by step. This procedure has the advantage that it allows quick identification and rejection of outlier data points. However, the errors compound from one step to another, which precludes a robust understanding of uncertainty in the final values of kinetic parameters. Instead in this work was used the maximum likelihood (ML) estimation for simultaneous estimation of all parameters of the nonlinear equations [27]. To implement ML method, one must assume an error distribution for the observed rate response. The next paragraphs will explain our choice of a model for the error variation.

Not unexpectedly, with the maximum and minimum observed rates differing by more than three orders of magnitude, the error variance increases markedly as the average rate increases. However, the error variance for $\ln$ (Rate) appears to be nearly constant across the range of all experimental conditions investigated. Further analysis of experimental variability of $\ln ($ Rate $)$ identified three sources of error. First, one source of errors is the imperfect control of experimental parameters during prolonged runs. For example, hourly variations in barometric pressure affect the actual value of $P_{\mathrm{H} 2 \mathrm{O}}$ in the oxidation chamber. Although small, these variations were present in all experiments. A second source of variation affecting all runs is measurement error in determining oxidation rate; this was most noticeable at lower temperatures and lower vapor pressures where the rate is slowest. In addition to these variations affecting each individual run, occasional large differences were observed between measured oxidation rates in parallel runs on different days, where the experimental conditions $\left(T, P_{\mathrm{H} 2 \mathrm{O}}, P_{\mathrm{H} 2}\right)$ were controlled to the best of our ability but a different graphite specimen was used. Microstructural differences between specimens, which translate in deviations of bulk density from the average values as observed for some samples, may explain local deviations of oxidation rates, such as faster oxidation rates for specimens with lower bulk density. 
Since a different graphite specimen was used each day for experimentation, the statistical model assumed independent errors of two types: a "day-to-day" error $(\delta)$ from variability of specimen properties, and a "within-day" error $(\varepsilon)$ to account for rate measurement error and incidental parameter variations during each run. The following logarithmic form of rate equation (1) was used:

$\ln ($ Rate $)=\ln \left(P_{\mathrm{H} 2 \mathrm{O}}\right)+\ln A_{1}-\frac{E_{1}}{R T}-\ln \left[1+\left(P_{\mathrm{H} 2}\right)^{0.5} \exp \left(\ln A_{2}-\frac{E_{2}}{R T}\right)+P_{\mathrm{H} 2 \mathrm{O}} \exp \left(\ln A_{3}-\frac{E_{3}}{R T}\right)\right]+\delta+\varepsilon$

where $\delta$ and $\varepsilon$ are independent, normally distributed error terms. The model (5) is a nonlinear mixedeffects model [28]. The ML estimates for the standard deviation of $\delta$ and $\varepsilon$ are 0.318 and 0.290 , respectively, obtained using PROC NLMIXED, a procedure of SAS software (Statistical Analysis Systems). The $95 \%$ confidence intervals are $0.318 \pm 0.083$ and $0.290 \pm 0.040$. The fact that $\delta$ 's estimated variability exceeds the estimated variability of $\varepsilon$ confirms that the material's heterogeneity as observed in the day-to-day term is a prominent source of variation. Figure 1 shows a plot of the residuals for the 48 days for which multiple observations were collected. Residuals were calculated as observed $\ln ($ Rate) minus predicted ln (Rate). Note the tendency for residuals to be similar for runs taken on the same day and thus from the same graphite specimen.

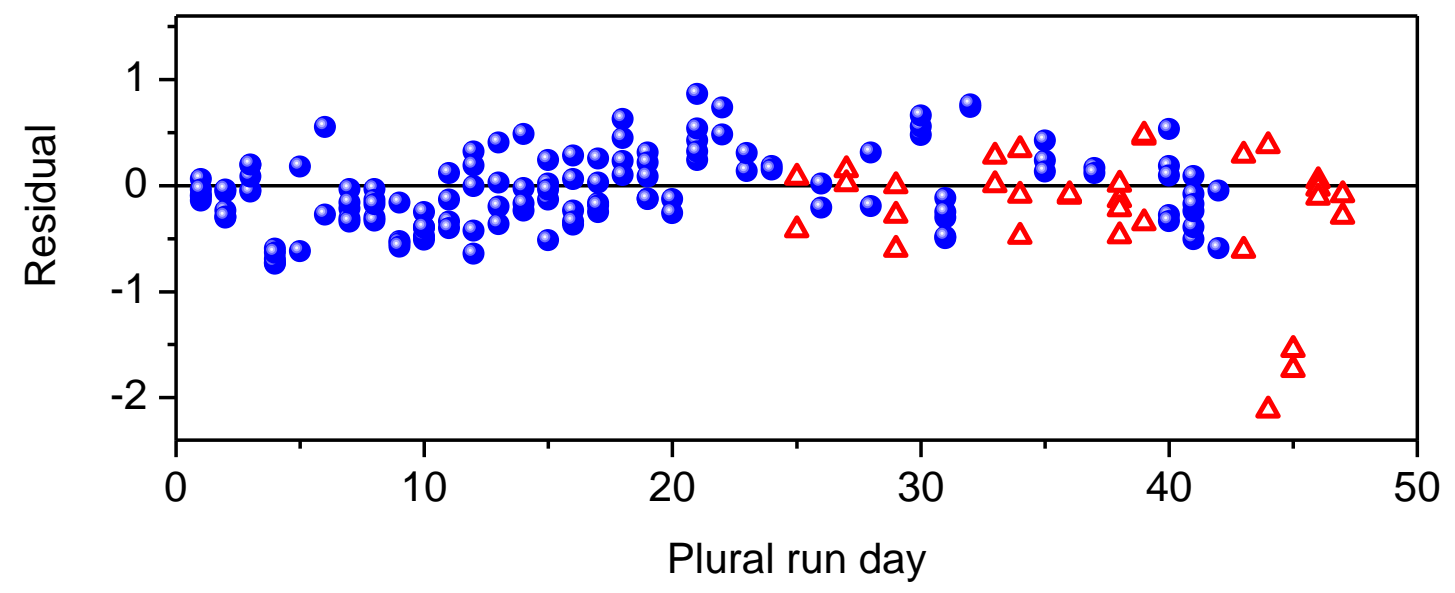

Figure 1: $\quad \ln ($ Rate $)$ residuals from fitting eq. (5), showing day-to-day and within-day variation. Solid blue circles are data at $P_{\mathrm{H} 2}=0$; open red triangles are data at $P_{\mathrm{H} 2}>0$.

As data were collected, it became clear that the non-linear form of the kinetic equation and the strong correlation between parameters made it necessary to collect data over a broad interval of $T, P_{\mathrm{H} 2 \mathrm{O}}$ 
and $P_{\mathrm{H} 2}$ in order to more accurately estimate the parameters. However, this was not entirely practical from an experimental point of view. The temperature range is limited: Oxidation by water becomes thermodynamically possible above $700{ }^{\circ} \mathrm{C}$. At $800{ }^{\circ} \mathrm{C}$ the oxidation rate is still very slow and measurements are affected by large errors. Above $1100{ }^{\circ} \mathrm{C}$ the reaction is fast, but the diffusional limitations may become important and might perturb the true kinetic regime. The useful temperature range is therefore between 900 and $1100{ }^{\circ} \mathrm{C}$. We collected a larger number of data at these two extreme temperatures, while varying $P_{\mathrm{H} 2 \mathrm{O}}$ and $P_{\mathrm{H} 2}$.

A total of 190 observations, collected from 76 specimens, were used to obtain estimates for the six parameters (activation energies and pre-exponential factors) of eq. (1). The estimates of the six parameters are reported in Table 2, along with 95\% confidence intervals. The confidence interval for each $A_{i}$ was obtained by taking the exponential of the endpoints of a confidence interval for $\ln \left(A_{i}\right)$; this explains why the ML estimate for each $A_{i}$ is not in the center of the corresponding confidence interval. For the parameter $E_{l}$ we are confident that the true value is within $13 \%$ of our estimate. No other parameter is estimated with similar relative precision. The components of $k_{2}$ are estimated with particularly weak precision. This is because the inhibiting effect of hydrogen is hardly noticeable for temperatures $\leq 1000^{\circ} \mathrm{C}$.

Table 2

Numerical values and confidence intervals of kinetic parameters in eq. (5) obtained for PCEA graphite by PROC NLMIXED, and corresponding parameters determined for H-451 graphite grade [10]

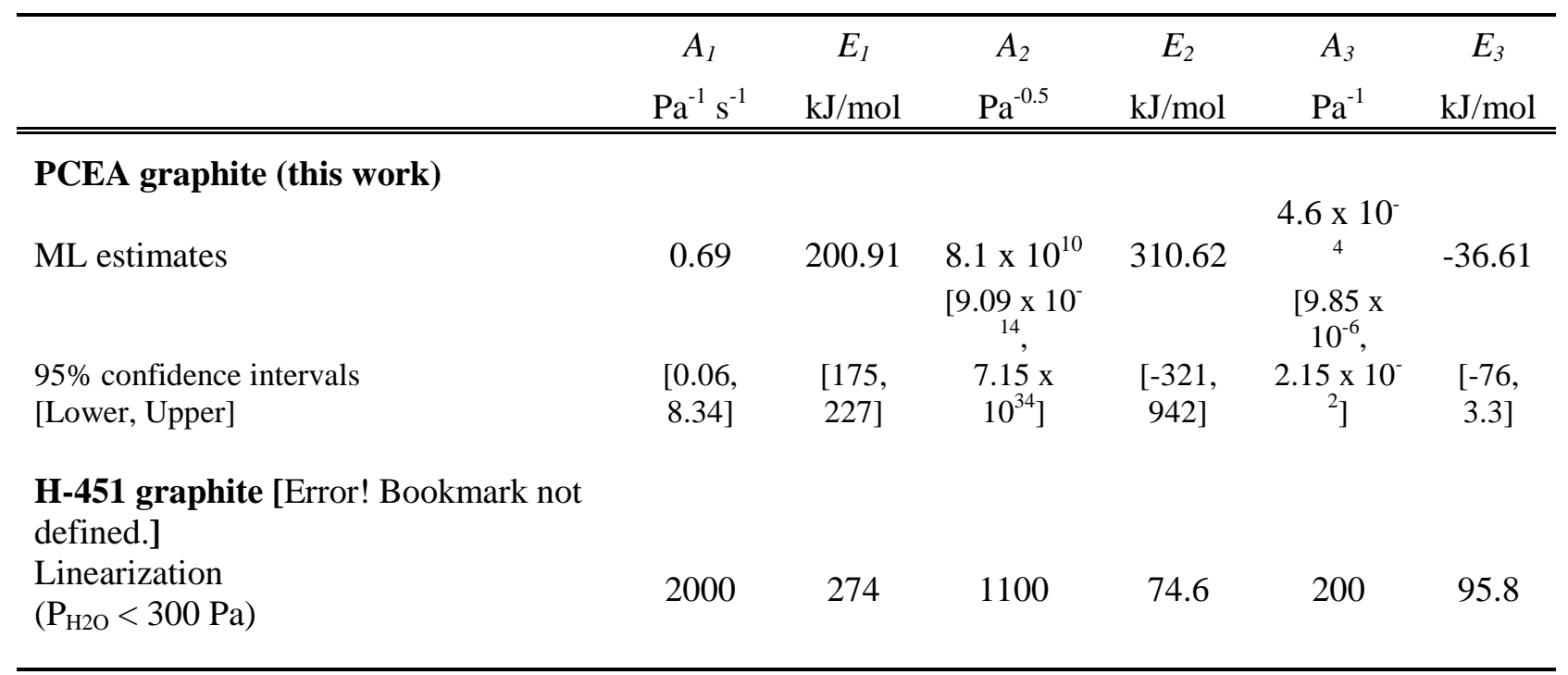


Figures 2 and 3 compare experimental data points with predicted rates as a function of temperature and $P_{\mathrm{H} 2 \mathrm{O}}$ at two conditions $\left(P_{\mathrm{H} 2}=0\right.$ and $\left.100 \mathrm{~Pa}\right)$. The most prominent scattering of data measured at identical conditions is attributed to material's inhomogeneity.

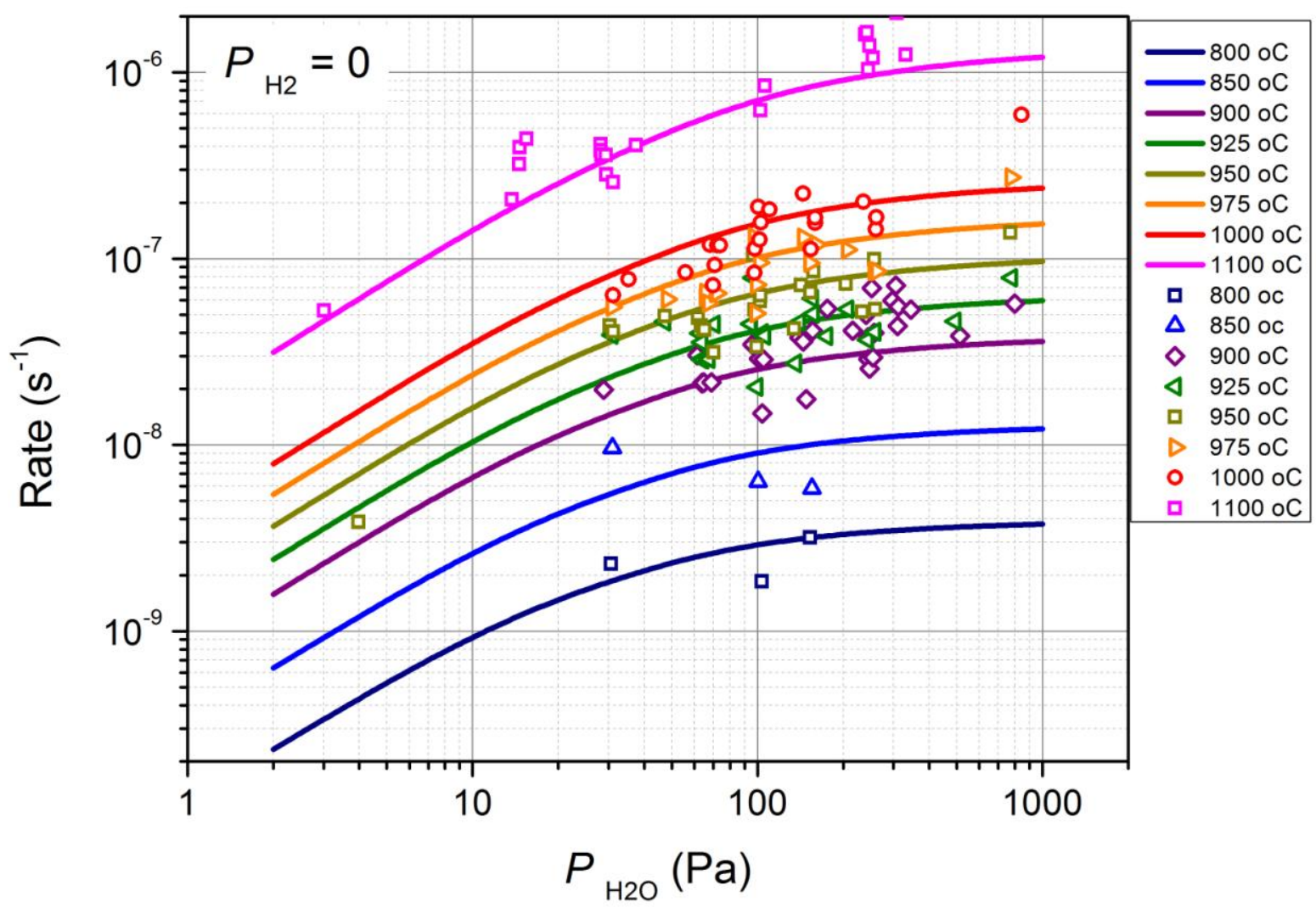

Figure 2: $\quad$ Comparison between measured oxidation rates at $P_{\mathrm{H} 2}=0$ (symbols) and predicted trends (lines) as a function of temperature and $P_{\mathrm{H} 2 \mathrm{O}}$. 


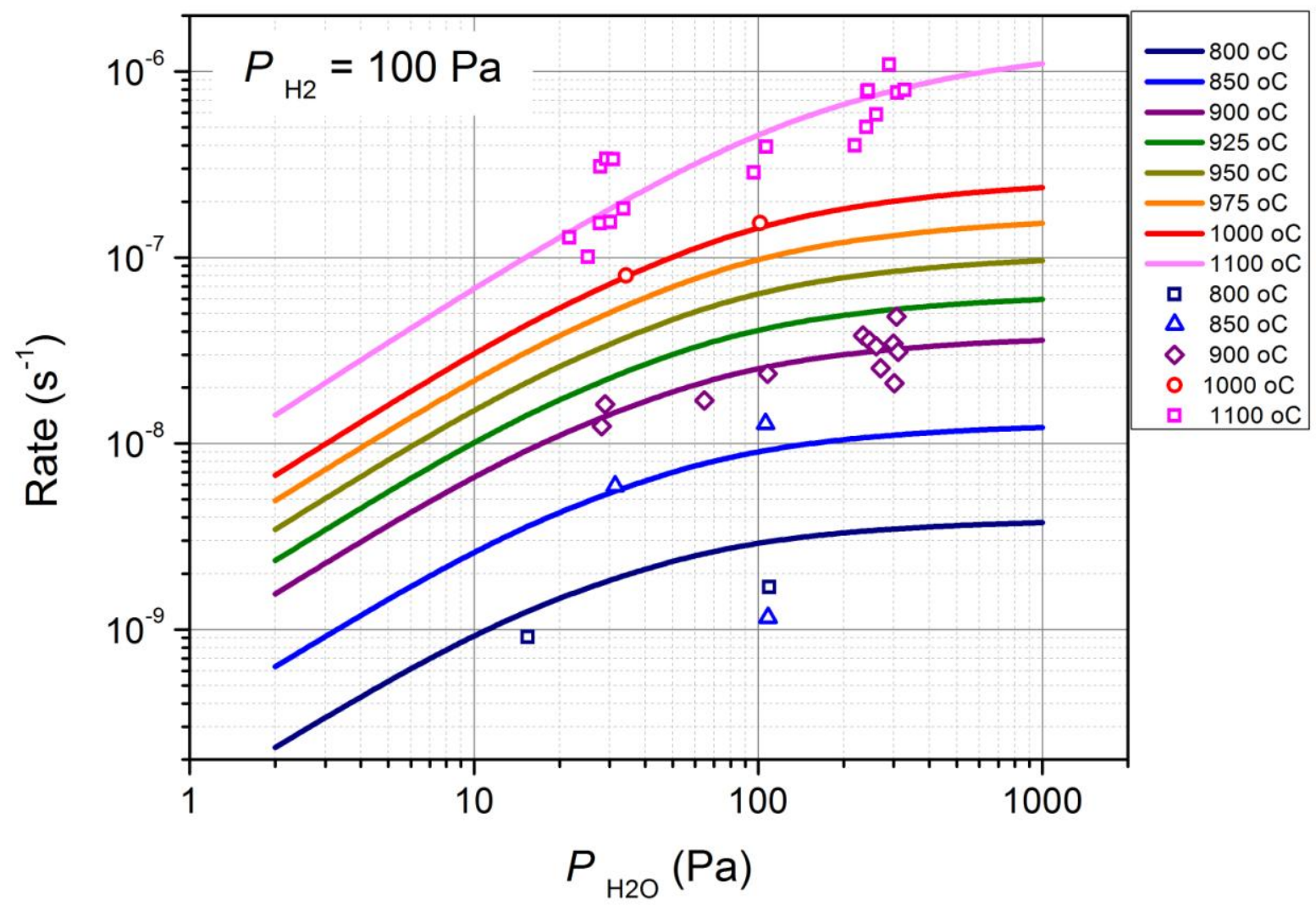

Figure 3: $\quad$ Comparison between measured oxidation rates at $P_{\mathrm{H} 2}=100 \mathrm{~Pa}$ (symbols) and predicted trends (lines) as a function of temperature and $P_{\mathrm{H} 2 \mathrm{O}}$ 


\section{Discussion}

\subsection{Significance of parameters}

The intricacy of kinetic equations for graphite oxidation by water consists in (i) the nonlinear character of eq. (1) with respect to pressures and temperature, and in (ii) the strong inter-dependence of $A_{i}$ and $E_{i}$ parameters according to eq. (2). In addition, the significance of rate constants $k_{i}$ depends on the exact reaction mechanism at the molecular level, as explained above. For this reason, all $A_{i}$ and $E_{i}$ should be regarded as apparent (or mechanism-conditioned) parameters, for which some unusual Arrhenius plots (variation of $\ln k_{i}$ vs. 1/T) might be observed. For example, in a study on graphite oxidation by $\mathrm{CO}_{2}$ (another classical example of the L-H type kinetics), Gadsby [7] obtained negative Arrhenius slopes for $k_{l}$ and $k_{3}$ (i.e. positive activation energies $E_{1}$ and $E_{3}$, as expected), but positive Arrhenius slope for $k_{2}$, suggesting that activation energy $E_{2}$ was negative. This is an unusual situation in formal chemical kinetics. Similarly, the temperature variation of rate constants $k_{i}$ reported by Burnette and Hightower [29] for oxidation by water of nuclear graphite 2020 suggests that both $E_{2}$ and $E_{3}$ are negative between 930 and $980{ }^{\circ} \mathrm{C}$ and $P_{H 2 O}<100 \mathrm{~Pa}$. In contrast, Velasquez et al [10] found positive values for all three $E_{i}$ parameters in gasification of $\mathrm{H}-451$ graphite by water between 820 and $980{ }^{\circ} \mathrm{C}$ and $P_{\mathrm{H} 2 \mathrm{O}}<300 \mathrm{~Pa}$. In this study it was found that only $E_{3}$ is negative for oxidation of PCEA graphite between 800 and $1100{ }^{\circ} \mathrm{C}$ and $15<P_{\mathrm{H} 2 \mathrm{O}}<800 \mathrm{~Pa}$. Based on the molecular mechanism shown in Scheme III, $E_{3}$ is negative if dissociative adsorption of $\mathrm{H}_{2} \mathrm{O}$ on free surface sites (i.e. $\mathrm{C}_{\mathrm{f}(\mathrm{s})}+\mathrm{H}_{2} \mathrm{O}(\mathrm{g}) \rightarrow \mathrm{C}(\mathrm{O})_{(\mathrm{s})}+\mathrm{H}_{2(\mathrm{~g})}$, with rate constant $i_{l}$ ) requires larger activation energy than desorption of surface oxygen complexes (i.e. $\mathrm{C}(\mathrm{O})_{(\mathrm{s})} \rightarrow$ $\mathrm{CO}(\mathrm{g})+\mathrm{C}_{\mathrm{f}(\mathrm{s})}$, with rate constant $i_{3}$ ). This is a plausible situation. Similarly, according to Scheme III, negative values of $E_{2}$ (as found for graphite 2020 [29]) are expected if breaking of C-H bonds from surface $\mathrm{C}(\mathrm{H})_{(\mathrm{s})}$ complexes is favored over dissociative chemisorption of $\mathrm{H}_{2}(\mathrm{~g})$.

\subsection{Non-transferability of kinetic parameters between graphite grades}

The parameter estimates for PCEA graphite and those for H-451 graphite are dramatically different (Table 2). Only the estimate for the critical parameter $E_{l}$ shows any resemblance. However, due to the nature of the L-H kinetic equation, different sets of parameters can provide comparable fitting of experimental results. The dependence between the six parameters in eq. (1) makes it difficult to obtain independent estimates with high confidence for the frequency factor and activation energy of each $k_{\mathrm{i}}$. This is a known feature of kinetic analysis of L-H type reactions. Thus, one must compare the predicted rates against measured rates for the two sets of kinetic parameter estimates in Table 2 to fully appreciate the similarity or differences. 
To evaluate the quality of the ML fit for PCEA graphite, we compare in Figure 4a oxidation rates measured in this work versus predicted rates at identical $\left(P_{\mathrm{H} 2 \mathrm{O}}, P_{\mathrm{H} 2}\right.$, and $\left.T\right)$ conditions. Figure $4 \mathrm{~b}$ shows rates measured for PCEA graphite versus predicted rates calculated with the kinetic parameters from the GA report [10] on oxidation of graphite H-451 by water. Because measured data extend over more than three orders of magnitude, the comparison is more convenient in logarithmic coordinates. Obviously, ML parameters estimates found in this work provide a good prediction of experimental data for PCEA graphite. The ML fit explains $91.6 \%$ of the variation in $\ln ($ Rate $)$, as calculated from the error sum of squares of (33.41) and the total sum of squares (399.81). On the other hand, the parameters reported for graphite H-451 do not fit experimental observations for graphite PCEA. Most rates measured in this work are systematically lower than predictions using $\mathrm{H}-451$ parameters. Using the reported $\mathrm{H}-451$ parameters to predict $\ln ($ Rate $)$ for PCEA graphite would explain just $63.5 \%$ of the variation in our 190 observations.

There are microstructure dissimilarities between the two graphite grades that may explain the difference in oxidation behavior. Like PCEA, the H-451 reference material is a medium grain, extruded nuclear graphite manufactured in USA (by SGL Carbon) from a petroleum coke precursor. Other properties are however different. One significant difference is the maximum grain size, which is smaller in PCEA $(0.8 \mathrm{~mm})$ than in $\mathrm{H}-451(1.25 \mathrm{~mm})$. The distribution of accessible pores in both graphites is bimodal (based on mercury intrusion porosimetry) but the range of narrow pores is shifted slightly towards larger values in H-451 (starting from $0.2 \mu \mathrm{m}$ ) compared to PCEA (starting from < $0.1 \mu \mathrm{m}$ ) [30]. Thus, it is plausible that the effective diffusion coefficient of water vapor is larger in H-451 than in PCEA, which may explain why H-451 shows faster oxidation rates at high temperatures, where increasingly faster chemical reaction rates are paralleled by a fast rate of diffusional transport. 


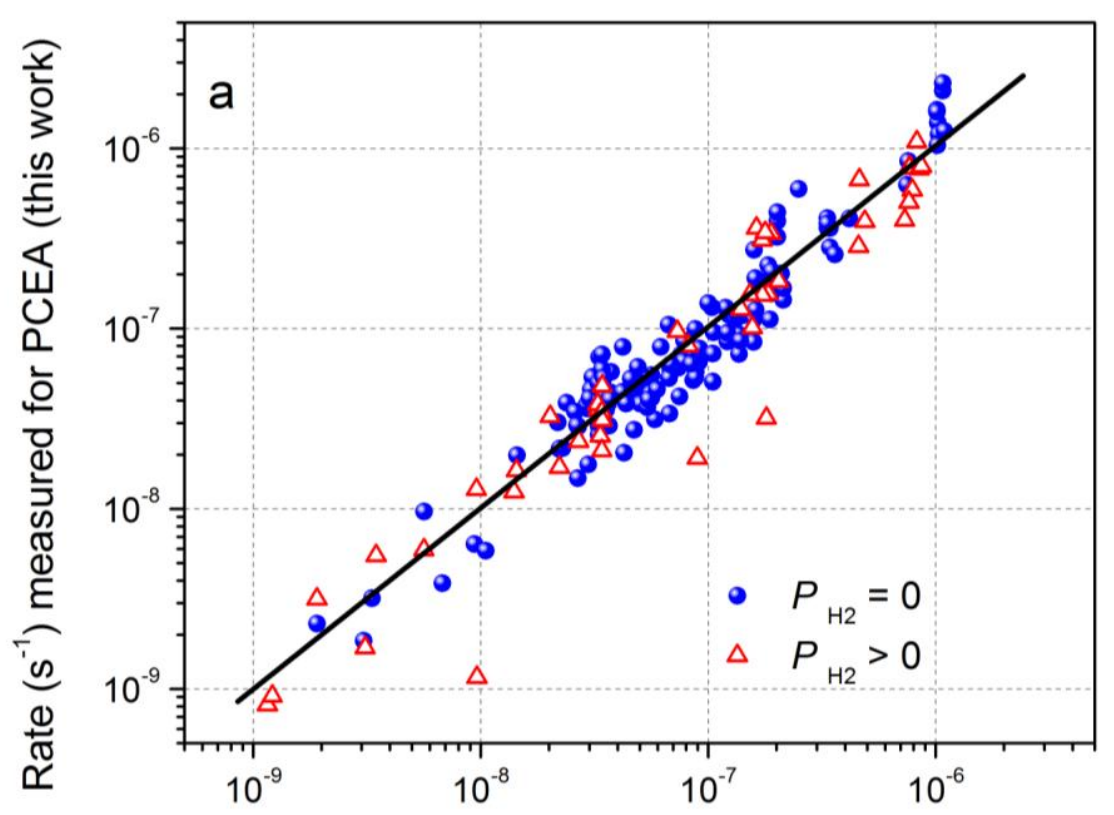

Rate $\left(\mathrm{s}^{-1}\right)$ predicted using MLE parameters (this work)

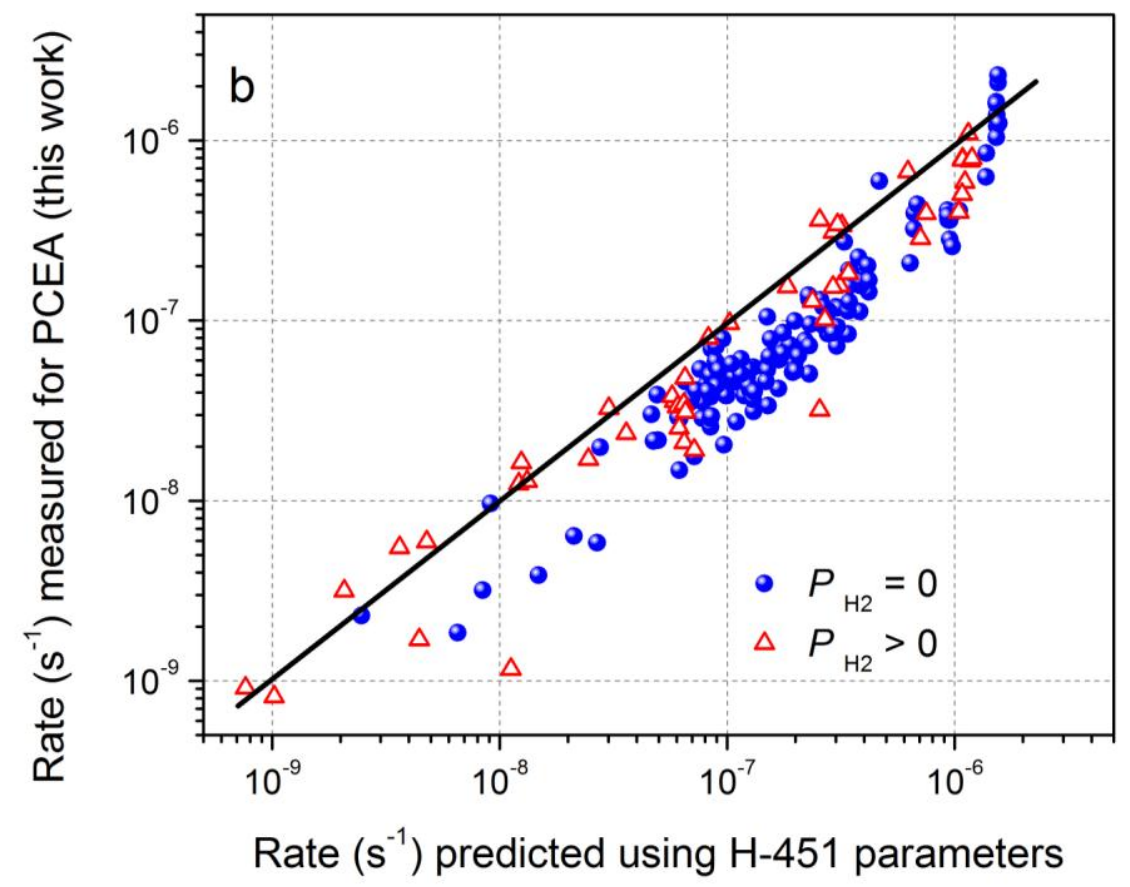

Figure 4: Comparison between oxidation rates of PCEA graphite measured in 190 experiments and rates predicted using (a) parameters found in this work and (b) parameters for graphite $\mathrm{H}$ 451from reference [10]. Blue circles are data at $P_{\mathrm{H} 2}=0$; red triangles are data at $P_{\mathrm{H} 2}>0$. Error sum of squares for $\ln ($ Rate) is 33.41 (in a) and 145.95 (in b). 


\subsection{Comparison of two graphite grades: PCEA and H-451}

In this subsection we compare the oxidation behavior of graphite PCEA and H-451 in similar conditions, using the parameters derived in this work for PCEA and those from the 1978 report for H-451 [10]. The authors of the GA report performed multiple kinetic measurements on graphite disks of variable thickness (1.6 to $12.7 \mathrm{~mm}$ ) using a gravimetric system. They confirmed that rates were not affected by diffusion for disks with thickness of $3.2 \mathrm{~mm}$ or less. Reaction rates were measured up to $980{ }^{\circ} \mathrm{C}$, at $P_{\mathrm{H} 2 \mathrm{O}}$ between 50 and $3000 \mathrm{~Pa}$, and $P_{\mathrm{H} 2}$ up to $500 \mathrm{~Pa}$. The final weight loss was in some instances up to $5 \%$. The L-H equations (1) and (2) were used with $n=0.75$. The kinetic parameters valid at $\mathrm{P}_{\mathrm{H} 2 \mathrm{O}}<300 \mathrm{~Pa}$ are shown in Table 2.

Figures 5 and 6 show predicted oxidation rates of PCEA and H-451 graphite grades at $0 \leq P_{\mathrm{H} 2 \mathrm{O}} \leq$ $50 \mathrm{~Pa}$ and $1 \leq P_{\mathrm{H} 2} \leq 10 \mathrm{~Pa}$ and at temperatures between 750 and $1100{ }^{\circ} \mathrm{C}$. Computations were made using parameters from Table 2. In the normal scale representation shown in Fig. 5 the nonlinear behavior of oxidation rates is clearly visible. However, in conditions specific to each graphite grade, and depending on the range of $P_{\mathrm{H} 2 \mathrm{O}}$ and $P_{\mathrm{H} 2}$, the simulations approach a quasi linear behavior. This is observed for $\mathrm{H}-451$ on a broader $P_{\mathrm{H} 2 \mathrm{O}}$ range, especially at low temperatures. For PCEA the linear approximation also holds, but on a narrower range of $P_{\mathrm{H} 2 \mathrm{O}}$ at low temperatures. At higher temperatures and high $P_{\mathrm{H} 2}$, the range of $P_{\mathrm{H} 2 \mathrm{O}}$ where linear approximation holds broadens. The linear behavior at certain conditions $\left(P_{\mathrm{H} 2 \mathrm{O}}, P_{\mathrm{H} 2}, T\right)$ justifies the use of a simplified equation for predicting oxidation behavior in normal operation conditions. This was the approach used by Wichner, Burchell and Contescu [15] in a study on penetration depth and transient conditions during graphite oxidation by moisture. Using the linear form of kinetic equation

$$
R=k_{o} P_{\mathrm{H} 2 \mathrm{O}}=A_{o} \exp \left(-\frac{E_{o}}{R T}\right) P_{\mathrm{H} 2 \mathrm{O}}
$$

is convenient because it makes possible analytical solutions of the mass balance equation in conditions of diffusional control of oxidation for evaluation of the temperature effect on the thickness of the oxidized layer in steady-state conditions. 


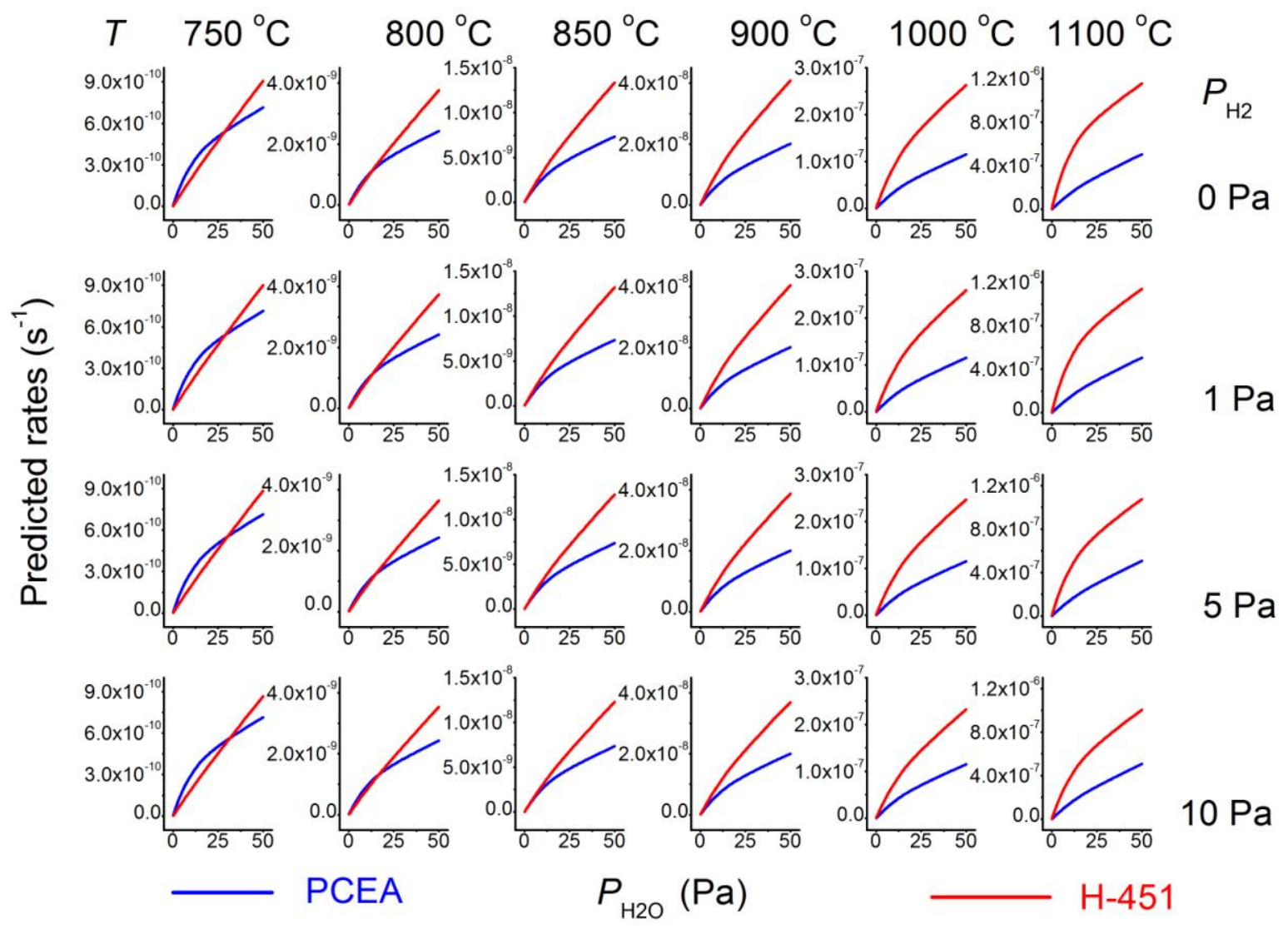

Figure 5: $\quad$ Comparison between predicted oxidation rates for PCEA graphite (this work) and H-451 reference [10] showing that external parameters $\left(P_{\mathrm{H} 2 \mathrm{O}}, P_{\mathrm{H} 2}\right.$ and $\left.T\right)$ have distinct effects on oxidation behavior of the two graphite grades.

\subsection{Oxidation behavior prediction for normal operating conditions}

The ultimate goal of parameter estimates from accelerated oxidation experiments is to predict oxidation rates in normal operating conditions, where it is not practical to perform experimental measurements because oxidation rates are extremely slow. Figure 6 compares oxidation rates predicted for PCEA and H-451 graphites at very low water pressures $\left(0.3<P_{\mathrm{H} 2 \mathrm{O}}<5 \mathrm{~Pa}\right)$, low temperatures $(750<$ $\left.T<950{ }^{\circ} \mathrm{C}\right)$ and constant hydrogen pressure $\left(P_{\mathrm{H} 2}=10 \mathrm{~Pa}\right)$. The representation in double logarithmic scale shows that, PCEA is more resistant to oxidation then $\mathrm{H}-451$ above about $850{ }^{\circ} \mathrm{C}$ and at very low water concentrations. However, simulations also show higher oxidation rates for PCEA at $750{ }^{\circ} \mathrm{C}$ and $800{ }^{\circ} \mathrm{C}$, where oxidation rates are respectively 2 times and 1.5 times faster compared to H- 451 . The plots on 
normal scale show the very strong effect of temperature and the nonlinear behavior at high $P_{\mathrm{H} 2 \mathrm{O}}$. The different behavior of the two graphite grades reflects microstructural and intrinsic reactivity factors.
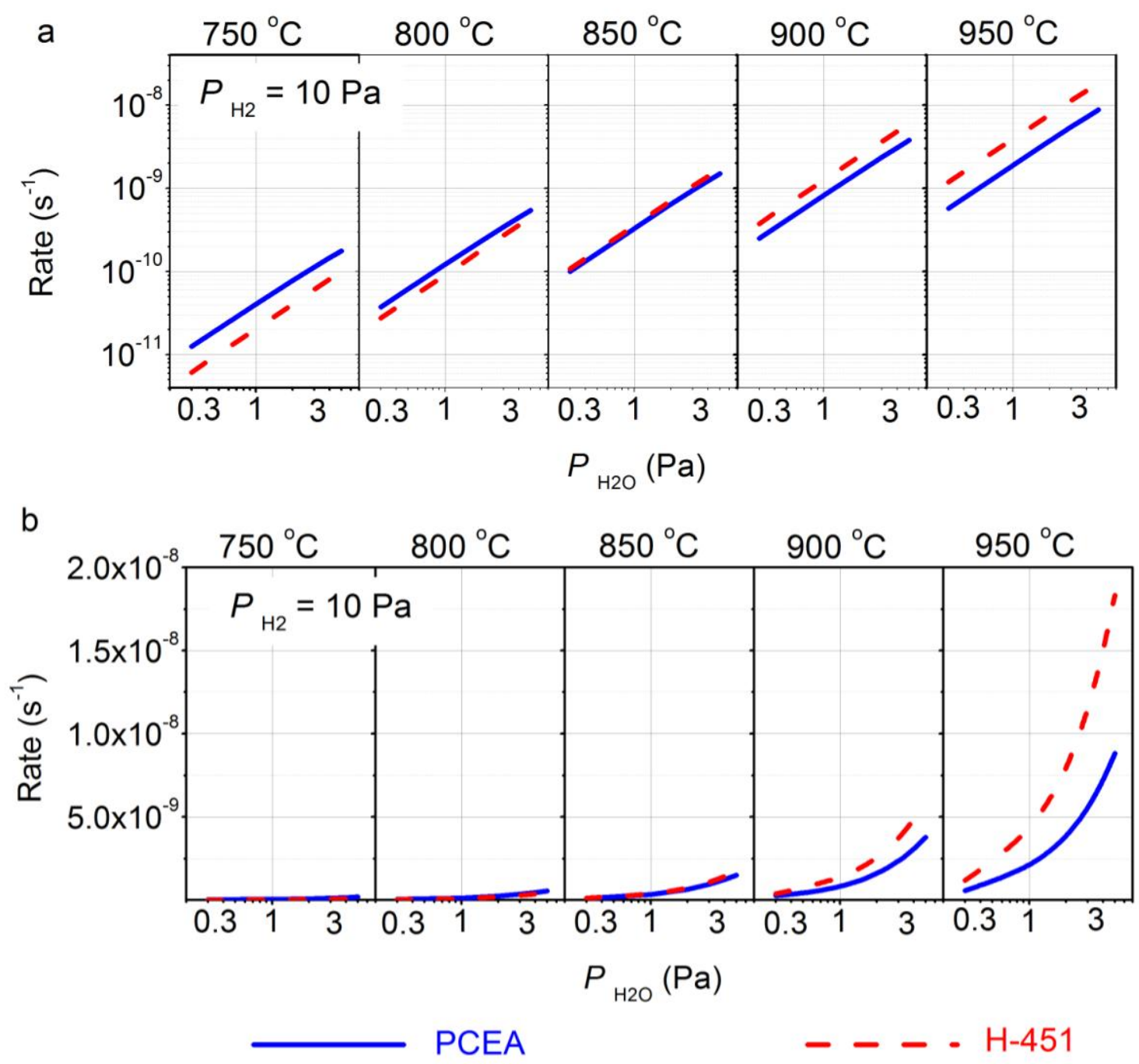

Figure 6: $\quad$ Predicted oxidation rates of PCEA (this work) and H-451 [Error! Bookmark not defined.] graphite grades in normal operating conditions

The fact that faster oxidation rates are predicted for PCEA at low $P_{\mathrm{H} 2 \mathrm{O}}$ might have positive consequences on the penetration depth of the oxidant (water). Using the linear form, equation (9), of the kinetic equation, Wichner, Burchell and Contescu $[15,16]$ derived an analytical model for estimation of oxidant penetration depth during transient oxidation by water vapor. In general, when oxidation rate is faster, but the supply of oxidant is limited (as in normal operating conditions) the penetration depth is 
expected to narrow. Blanchard [31] identified two oxidation regimes where the extent of gasification is limited by the rate of supply of oxidant (rate balance controlled regime) or by the fixed amount of oxidant available in a closed system, for example after blowing down and recharging the coolant (mass balance controlled regime). In these conditions, which are typical for normal VHTR operation, the location and the rate of oxidation is controlled by the balance between the rate of inwards diffusion of the oxidant and the rate of in-pore gasification by which the oxidant is consumed. The former is controlled by the effective diffusivity of the oxidant species in the pore structure of graphite. The latter is the chemical oxidation rate, whose parameters are now available for graphite H-451[10] and PCEA (this work). Using simple assumptions on the diffusion coefficient, the model developed by Wichner et al. $[15,16]$ shows that faster reaction rates and low oxidant supply rates cause large concentration gradients and steep oxidant depletion profiles under the exposed surface. According to this model, the effect of the oxidation temperature on the penetration depth $X_{\beta}$ where the oxidant concentration drops from the external surface value to a certain fraction $\beta$ follows the approximate relationship $X_{\beta} \approx \exp \left(E_{o} / R T\right)$ where $E_{o}$ is the activation energy in the linearized rate equation (9). Assuming $E_{\mathrm{o}} \approx E_{1}$ the values in Table 2 suggest lower penetration depth for PCEA than for H-451. Practically, the faster the oxidation rate, the narrower is the penetration depth in equal conditions. At low temperatures, where PCEA has faster oxidation rates than $\mathrm{H}-451$, it is expected that PCEA will develop a thinner oxidation layer at steady state conditions. On the other hand, slower oxidation rates of PCEA at high temperatures will favor deeper penetration of the oxidant in the improbable event of water (steam) ingress. Thus, oxidation at high temperatures might be more damaging on mechanical strength of PCEA than of H-451 components, although the oxidation rate of the former would be slower. Other factors, such as the structural characteristics (porosity fraction, tortuosity of pore channels) of specific graphite grades, are expected to modify the effective diffusivity of the oxidant and thus introduce differences in the thickness of the oxidized layer. These differences will be addressed in a future communication, which will compare penetration depth during chronic oxidation by water of PCEA and H-451 graphite grades, based on the above-mentioned model developed by Wichner et al. $[15,16]$. At this time, a rough estimate indicates that the active oxidation depth will still be in the range of 2-3 $\mathrm{mm}$ at $750{ }^{\circ} \mathrm{C}$ and 1 bar coolant total pressure. They are expected to decrease significantly at higher coolant pressures.

\section{Conclusion}

This paper reports results of accelerated kinetic measurements of PCEA graphite oxidation by low concentrations of water vapor and hydrogen in pure helium. To the authors' best knowledge, such a study has not been done since the seminal work of Velasquez, Hightower and Burnette at General Atomic 
Company in 1978 using the American grade nuclear graphite H-451. The test conditions were chosen as close as possible to the normal operating conditions, although on the high side of the temperature range $\left(900-1100{ }^{\circ} \mathrm{C}\right)$, water pressures $(15-750 \mathrm{~Pa})$ and hydrogen pressures $(30-150 \mathrm{~Pa})$. These conditions were needed in order to obtain measurable rates and to collect a statistically significant number of observations during the normal duration of the project. The size of graphite specimens was small enough to reduce diffusional effects that otherwise would negatively impact on kinetic measurements. This choice had, however, the disadvantage that the local inhomogeneity of graphite microstructure had influenced the results and introduced random errors in the rate measurements.

Data analysis was performed using the statistical method based on maximum likelihood estimation of parameters and simultaneous fitting of non-linear equations. From the comparison of oxidation rates predicted for normal operating conditions between PCEA and H-451 graphites it appears that PCEA is more resistant to oxidation by moisture above $850{ }^{\circ} \mathrm{C}$. However, at lower temperatures simulations show faster oxidation rates for PCEA. The difference in oxidation rates is expected to cause thinner oxidized layers on the surface of PCEA components during typical normal operating conditions $\left(700-800{ }^{\circ} \mathrm{C}, P_{\mathrm{H} 2 \mathrm{O}}<1 \mathrm{~Pa}\right)$. The results presented here provide the basis for development of predictive models for oxidation by moisture of particular grades of graphite (PCEA in this case) during normal operation of HTGR.

\section{Acknowledgement}

This work was supported by the U.S. Department of Energy, Office of Nuclear Energy Science and Technology under contract DE-AC05-00OR22725 with Oak Ridge National Laboratories managed by UT-Battelle, LLC. The authors acknowledge encouragement and support from Dr. Pete Pappano (U.S. Department of Energy) and Dr. William Windes (Idaho National Laboratory). A long-lasting collaboration with Dr. Robert Wichner (Oak Ridge National Laboratory, retired), who contributed significantly with planning the experiments and interpretation of results, is gratefully acknowledged.

\section{References}

1 M. P. Kissane, Nucl. Eng. Des. 239 (2009) 3076-3091.

2 X. Yu, S. Yu, Nucl. Eng. Des. 240 (2010) 738-743.

3 W. R. Corwin, Generation IV reactors integrated materials technology program plan: Focus on very high temperature reactor materials, ORNL/TM-2008/129, Oak Ridge, TN, 2008. 
4 B. Castle, NGNP reactor coolant chemistry control study, INL/EXT-10-10533, Idaho Falls, ID, 2010.

5 R. N. Wright, Kinetics of gas reactions and environmental degradation in NGNP helium. INL/EXT-06-11494, Idaho Falls, ID, 2006.

6 J. Gadsby, C. N. Hinshelwood, K. W. Sykes, Proc Roy Soc (London) A 187 (1946) 129-151.

7 J. Gadsby, F. J. Long, P. Sleightholmm K. W. Sykes, Proc Roy Soc (London) A 193 (1949) 356-376.

8 L. G. Overholser, J. P. Blakely, Carbon 2 (1965) 385-394.

9 J. P. Blakely, L. G. Overholser, Carbon 3 (1965) 269-275.

10 C. Velasquez, G. Hightower, R. Burnette, The oxidation of H-451 graphite by steam. Part 1: Reaction kinetics, General Atomic Company, GA-A14951, San Diego, CA, 1978.

11 M. B. Richards, Energy 15 (1990) 729-739.

12 X. Yu, L. Brissoneau, C. Bourdeloie, S. Yu, Nucl Eng Design 238 (2008) 2230-2238

13 X. Luo, J-C Robin, S. Yu, Nucl Eng Des 236 (2006) 938-947.

14 M. Eto, T. Kurosawa, Estimation of graphite materials corrosion with water-vapor in coolant of VHTR and oxidation effect on the materials properties, in Specialists' Meeting on Graphite Component Structural Design. JAERI Tokai (Japan) September 8-11, 1986, IWGGR-11: 189-194.

15 R. P. Wichner, T. D. Burchell, C. I. Contescu, J Nucl Mater 393 (2009) 518-521.

16 R. P. Wichner, T. D. Burchell, C. I. Contescu, A note on the oxidation of graphite by $\mathrm{O}_{2}$ and moisture, ORNL/TM-2008/230, Oak Ridge, TN, 2008.

17 C. I. Contescu, T. Guldan, P. Wang, T. D. Burchell, Carbon 50 (2012) 3354-3366.

18 R. Moormann, H. K. Hinssen, K. Kuhn, Nucl Eng Design 237 (2004) 281-284.

19 X. Luo, J-C Robin, S. Yu, Nucl Sci Eng 151 (2005) 121-127.

20 S-H Chi, G-C Kim, J Nucl Mater 381 (2008) 9-14.

21 M. S. El-Genk, J-M Tournier, J Nucl Mater 420 (2012) 141-158.

22 J. Kane, C. Karthik, D. P. Butt, W. E. Windes, R. Ubic, J Nucl Mater 415 (2011) 189-197.

23 R. C. Giberson, J. P. Walker, Carbon 3 (1966) 521-525.

24 T. X. Nguyen, J-S Bae, Y. Wang, S. K. Bhatia, Langmuir 25 (2009) 4314-4319.

25 F. H. Yang, R. T. Yang, Carbon 40 (2002) 437-444.

26 C. I. Contescu, T. D. Burchell, Research needs and test plan for characterization of nuclear graphite oxidation, ORNL/TM-2012/263, Oak Ridge, TN, 2012.

27 G. A. F. Seber, C. J. Wild, Nonlinear Regression, John Wiley, New York, 1989. 
28 J. C. Pinheiro. D. M. Bates, Mixed-Effects Models in S and S PLUS, Springer, New York, 2000 .

29 R. D. Burnette, G. R. Hightower, Oxidation kinetics of SC 2020 graphite nuclear grade, lot 1, GA Document 908030/0, May 31, 1985; See also Graphite Design Handbook, DOE-HTGR88111, General Atomics, 1988.

30 T. D. Burchell, S. Nunn, J. Strizak, M. Williams, AGC-1 sister specimen testing data report, ORNL/TM-2009/025, Oak Ridge, TN, 2009.

31 A. Blanchard, The thermal oxidation of graphite, in: Irradiation damage in graphite due to fast neutrons in fission and fusion systems, Appendix 2, IAEA-TECDOC-1152, Vienna, 2000. 